\title{
PECULIARITIES OF FORMING GENERAL CULTURAL COMPETENCES IN STUDENTS OF INSTITUTIONS OF HIGHER TECHNICAL EDUCATION BY MEANS OF INTERDISCIPLINARY INTEGRATION
}

\author{
Oksana V. Danilova* \\ Ufa State Petroleum Technological University, Branch of the University in the City of Oktyabrsky, Russian Federation
}

\begin{abstract}
Timeliness of the problem being studied is determined by a necessity to form general cultural competences of students of institutions of higher technical education, as changes in society, social and economic life of the country lead to shifting the values and, simultaneously, to decrease in the cultural level of people. The paper is aimed as looking for new ways within the educational system of the institution of higher technical education, directed towards humanization and humanitarization of higher education that is to facilitate development of general cultural competences and optimization of the higher technical education as a whole. The leading method of study of this problem is a pedagogical experiment that allows for revealing as well as giving theoretic justification and experimental confirmation of the maturity level of the general cultural competences of technical students during the learning process. The research sees the interdisciplinary approach as an important pedagogical subsystem of the learning process, built with considerations for its essential characteristics on the foundation of competency-building and student-centered approaches; at that, some pedagogical conditions are implemented in the form of intersubjective relationships being built between an instructor and their students. The scientific and methodological material presented in the paper and used during binary lectures and practical sessions facilitate development of the general cultural competences during theoretical studies.
\end{abstract}

\section{Introduction}

Changes in the society at the current stage demand that universities of the country prepare highly qualified specialists. The modern labor market imposes increasing requirement to the quality of higher education, leading to competition between alumni of various institutions, thus implementation of the competency-building approach has been started in the Russian higher professional education, aiming at developing student's competences drawn on the basis of professional standards.

In the context of that, we believe that interdisciplinary approaches are especially timely for higher technical education institutions.

The value of interdisciplinary links increases due to increased amounts of scientific and practical information.

Many scholars believe that the general cultural competences are best formed in students by means of interdisciplinary integration, as the students get an attitude to systematic extension of knowledge, thus, binary and integrated lectures will we among the pedagogical conditions aimed at formation of the general cultural competences in technical students.
Other general requirements to the general cultural competences may be reduced to an ability to independently solve complex and innovative engineering problems. Accreditation of educational programs facilitates improvement and further development of education.

General cultural competences are designed on the foundation of humanitarian culture; however, the understanding of competences as implemented in the modern educational standards is not adapted to it. Such highly generalized definition of competences leave much freedom to educational outcomes to the higher education institutions in planning, organization and changes. Freedom in determining educational objectives and outcomes requires solving some conceptually new tasks in higher education teaching activities [1-8].

\section{Results and discussion}

Currently, competence nature of interdisciplinary integration is not comprehended completely in the Russian higher education, as there are no well-developed approaches to theory and methodology of the professional education that would allow implementing

* Corresponding author: oks-danil@yandex.ru 
its inherent potential; besides, there are no technologies aimed at formation of the general cultural competence of students.

However, the authors, just as many other researchers in the field, hold that formation of the general cultural competence of a future technical specialist is impossible without contextualized learning and use of interdisciplinary links. In contextualized learning, there is a modeling of professional and social components of future engineering activities, while the interdisciplinary integration, in its turn, serves as a joining link for various fields of science [9-13].

Besides, nowadays there is a necessity in research activities aimed at increasing the total amount of theoretical knowledge, scientific breakthroughs that may become foundations of innovative production technologies. A modern graduate, future technical specialist shall be capable of complex application of knowledge obtained from various disciplines.

Scientific and pedagogical literature has no uniform definition of interdisciplinary integration, thus, its role and place among the pedagogical categories may be defined differently.

Referencing opinions of a number of scholars, we may affirm, that the interdisciplinary link is a process of community of student courses that reflects unified, continuous and integral phenomena of professional life [12].

We see interdisciplinary integration as the highest form of communality in objectives, principles and meaning of education, creation of massive interconnection of all the subjects of an educational program. Thus, we hold that the general cultural competence shall be developed starting from the first stage of student training. It is necessarily so, that by the final year, they have formed a skill of independent activity aimed at timely finding optimal solutions in any complex professional situations. In the higher technical education institution, it may be implemented by means of comprehensive interdisciplinary link. Initially, a team may be formed of students of various majors, who while solving together various class assignments and research tasks will not only master the features of their future profession, but develop communicative capabilities and practice team work. This may me attained during Student Scientific Research and complex course projects. The tasks of academics is in directing the students to independent and creative activities, to searching for solutions of a certain problem from various points of view, to implement their own ideas. The students shall understand that working on the task together they may form an innovative project implementation model. In addition, prospectively, the academics may plan for defense of complex project final works of the students in their steering documents; during the defense, the students shall demonstrate their interdisciplinary projects. While preparing the projects, each of the students will solve their own highly specialized task, sharing and adjusting their results with the other members of their team as necessary for completion of the common work.

\subsection{Preliminary results}

Theoretical and experimental methods were employed in the research: analysis of pedagogical, psychological and methodological literature on the subject of the research; didactic modeling method, conversation, surveying, questionnaire, testing of students, observation, generalization of teaching experience, pedagogical experiment, analysis and generalization of experimental data, statistical methods. The statistical methods included statistical processing of data obtained in the experiment.

A branch of the Ufa State Petroleum Technological University in Oktyabrsky, the Republic of Bashkortostan served as an experimental site of the research. The study covered 70 students.

The research was carried out in three stages.

At the first stage, available sources in Russian and foreign literature on the subject of research were analyzed; best practices of institutions of higher education (both technical and humanitarian) were studied; modern requirements to the professional training of technical students were analyzed; general cultural competences were identified and justified; pedagogical conditions were obtained and justified.

At the second stage, an educational experiment was conducted to check the devised pedagogical conditions for development of general cultural competences.

The third stage of the research involved verification, analysis and processing of the experimental results; verification of efficiency of the pedagogical conditions aimed at formation of the general cultural competences when giving responses, during independent and review works; generalization of results obtained in the experiment; elaboration of research conclusions.

In our research, a competence is an ability to apply skills and knowledge for successful activity in a certain field, a capability to perform professional function, meeting the requirements specified for a certain position. The concept of the general cultural competence may be represented as a capability to master new knowledge, skills, practices, abilities; a possibility of efficient employment of capabilities during the professional activity; also, integration in the field of knowledge and skills, presence of personal traits.

From the perspective of research conducted by pedagogical scholars $[9,10]$, we defined and proposed a criteria-based composition of the general cultural competence development, consisting of cognitive, operational, motivational value-based and reflexive assessment criteria. The foundation of the motivational value-based criterion is a system of motivational and value-based attitudes of the student, towards themselves and their activity. It characterizes the student's need in research activity, cognitive activity, need for independence during the cognition, decision-making and its assessment. The cognitive criterion represents a system of knowledge that facilitates formation of a scientific world view in students. This criterion provides the students with methodological skills, which provide a student easy understanding of study material and organizing their independent cognitive activity. 
Operational criterion is manifested in traits necessary to comprehend the objectives of the interdisciplinary classes, creative abilities, as well as in the vision of the problem, posing the question, proposing a hypothesis, an ability to present the material in a structured fashion. Reflexive assessment criterion represents a comprehensible attitude of the students to the results of the training, ability to assess their own results and those of their peers.

A development indicator of the motivation valuebased criterion is the level of interest to the future profession. The level of obtained knowledge is a development indicator of the cognitive criterion, while for the operational criterion it is the level of independent cognitive activity. Reflexive assessment criterion is characterized with a degree of adequate assessment of competence development results. Each criterion is represented with three levels: low, average and high.

In our research, formation of the general cultural competences through the knowledge obtained in interdisciplinary sessions is implemented through an interrelation of the main principles of systemic, studentcentered and activity approaches.

The student-centered approach creates conditions for student's development as an active subject, capable of implementing their way of life and personal essence in the learning situation and in their future professional life alike. Actualization of the student-centered approach manifests in conditions of student's independent determination and comprehension of means and conditions of their activity, provision of the students with subjective position in the educational process, building a system of relations between the instructor and the students on the foundation of openness, trust and dialog. Educational process efficiency depends on involvement of the students into learning situation, as the personality is developed and manifested in activity. Organizing the activity of the students, the instructor develops social and professional experience of the students, their functions and capabilities.

The fundamental principles of the methodological approaches have become a foundation for implementation of organizational and pedagogical conditions: creation of inter-subjective relations, use of differentiated tasks, monitoring of the learning process.

In our study, the inter-subjective relations are business relations of equal partners in joint activity, which are built on the basis of support, trust and cooperation. The students, being subjects of learning and cognitive activity, shall know how this activity is performed.

Efficiency of development of the inter-subjective relations is influenced by subjective characteristics of instructors: ability to build relations on the foundation of a dialog, professional and pedagogical skills and knowledge, personal traits, orientation towards mutual understanding and trust.

The third pedagogical condition of development of the general cultural competences is the learning situation monitoring, which is a regular and systematic procedure for collection, storage, processing and distribution of information on the education system. The monitoring allows timely tracking and correction of the learning process, which becomes controllable.

\subsection{Experiment}

At the ascertaining stage of the experiment, factors and conditions were revealed that have influence on the development level of the general cultural competences.

For disciplines of the humanities, a set of general cultural competences was determined that shall be formed in the students.

For all the disciplines of the humanities, there are provisions for interdisciplinary lectures and practical sessions.

At the ascertaining stage of the experiment carried out on the intramural students we used logic and heuristic maneuvers, as well as vortcombinatorial ones, allowing actualizing creative abilities of the students. The following were nominated as the organizational forms: massive (binary interdisciplinary lectures), group (practical sessions using learning through lay and interdisciplinary capacity) and individual (conversations).

In addition, at this stage we conducted questionnaire to determine the development level of the humanitarian motivation level, which has direct influence over formation of the general cultural competences of students. The questionnaire, conducted among the second year intramural students of the Oktyabrsky branch of the Ufa State Petroleum Technological University, has shown, that all the students questioned pertain to the average level of subjective control development. This indicator informs, that the students are as capable of taking responsibility in complex situation, as shedding the responsibility and laying it on others.

The development level of the cognitive component was determined during the questionnaire, from results of instructor-developed tests, answers to questions, performance of final projects, and taking into consideration the degree of student's activity in class.

At the ascertaining stage of the experiment, a complex of pedagogical conditions for formation of the general cultural competences was implemented. At the initial stage of the competence formation, the most important general cultural competences were determined on the foundation of the requirements of state educational standards. Then, the ascertaining experiment proceeded in the following way: pedagogical technologies were applied aimed at competence development; an educational environment was formed where the students and the instructors participated as equal subject of the learning process; the learning process was monitored.

The experimental research covered students majoring in Oil and Gas Industry, (code 131000), training program Operation and Maintenance of Oil-Producing Facilities. In accordance with the experiment objectives, two groups were formed: BGR 16-11 and BGR 16-12.

After conducting group interviews, testing, questionnaires aimed at revealing the initial level of 
command of the general cultural competences, it was found out, that in the BGR 16-12 group the level of the humanitarian culture was higher, and as the general cultural competences are built on the foundation of the humanitarian culture. We defined the BGU 16-12 group as the control group (CG), while the BGR 16-11 group served as the exposure group (EG).

Table 1. Level of maturity of the general cultural competences (GC) in students

\begin{tabular}{|c|c|c|c|}
\hline \multirow{2}{*}{$\begin{array}{c}\text { Motivation } \\
\text { to studying }\end{array}$} & \multicolumn{3}{|c|}{ Level } \\
\cline { 2 - 4 } & \multirow{2}{*}{ low } & average & high \\
\hline Groups & $22 \%$ & $51 \%$ & $27 \%$ \\
\hline CG & $17 \%$ & $57 \%$ & $26 \%$ \\
\hline EG & &
\end{tabular}

Motivation to studying manifesting in interest to study is also a foundation of the motivational valuebased criterion of formation of the general cultural competences. At the initial stage of the experiment, the following data were obtained:

Table 2. Student's motivation for studying various disciplines by cycle

\begin{tabular}{|c|c|c|}
\hline $\begin{array}{c}\text { Motivation } \\
\text { to knowledge }\end{array}$ & $\begin{array}{c}\text { CG } \\
\text { start }\end{array}$ & $\begin{array}{c}35 \text { persons } \\
\text { start }\end{array}$ \\
\cline { 2 - 3 } humanities & $26 \%$ & $23 \%$ \\
\hline natural sciences & $32 \%$ & $30 \%$ \\
\hline technical sciences & $32 \%$ & $32 \%$ \\
\hline $\begin{array}{c}\text { lack of } \\
\text { motivation to studying }\end{array}$ & $8 \%$ & $15 \%$ \\
\hline
\end{tabular}

We believe that the foundation for formation of the humanitarian culture of students is laid during the lectures, as they give a possibility to introduce the students to the general culture and the humanitarian culture in particular. That is why during the implementation of the first pedagogical condition (creation of inter-subjective relations between the students and the instructors), we welcomed sincerity and genuineness in communication, insistence, benevolence, tactfulness and commitment to creation of equal relations.

Throughout the experimental work, the instructors aspired to develop communicative and reflexive skills in the EG students. The students got a possibility to ask, independently perceive, comprehend the necessary information, as well as obtained necessary skills in reasoning and defending their point of view. Dialogic communication during the interdisciplinary sessions facilitated more deliberate creative mastering of material, favorable climate in sessions, and development of equal and open relations.

During the ascertaining experiment, we succeeded to open new aspects in binary lectures. The novelty of our approach to conducting this part of the experimental work is in the fact, that inclusion of binary and integrated lectures in various disciplines delivered by lecturers from different department has built a kind of a linking bridge between seemingly different disciplines, thus helping the students not only mastering the material, but finding the connections between subjects in humanities and engineering. In the future, this will help them to rationally consider issues during their professional life.

During the ascertaining experiment, we succeeded in developing the small-group communicative skills in students during the practical sessions; creative approaches shown by students in many tasks helped reveal the level of knowledge pertaining to humanities.

At the final stage of the ascertaining experiment aimed at formation of the general cultural competences in the students of the Oktyabrsky branch of the Ufa State Petroleum Technological University, we conducted analytical and correctional pedagogical activities. On the foundation of criteria of the general culture competence development that we had devised during the initial stage, we conducted a comparative analysis of results obtained in EG and CG.

Table 3 Comparative characteristic of the general cultural competences development level (GC) in students

\begin{tabular}{|c|c|c|c|c|c|c|}
\hline \multirow{2}{*}{$\begin{array}{c}\text { Motivation } \\
\text { to } \\
\text { knowledge }\end{array}$} & \multicolumn{2}{|c|}{ CG } & \multicolumn{2}{c|}{ EG } & \multicolumn{2}{c|}{$\begin{array}{c}\text { Compari } \\
\text { son of } \\
\text { results }\end{array}$} \\
\cline { 2 - 7 } & start & end & start & end & $\begin{array}{c}\text { C } \\
\text { G }\end{array}$ & EG \\
\hline humanities & $26 \%$ & $27 \%$ & $23 \%$ & $30 \%$ & $\begin{array}{c}1 \\
\%\end{array}$ & $7 \%$ \\
\hline $\begin{array}{c}\text { natural } \\
\text { sciences }\end{array}$ & $32 \%$ & $34 \%$ & $30 \%$ & $35 \%$ & $\begin{array}{c}2 \\
\%\end{array}$ & $5 \%$ \\
\hline $\begin{array}{c}\text { technical } \\
\text { sciences }\end{array}$ & $34 \%$ & $35 \%$ & $32 \%$ & $35 \%$ & $\begin{array}{c}1 \\
\%\end{array}$ & $3 \%$ \\
\hline $\begin{array}{c}\text { no } \\
\text { motivation }\end{array}$ & $8 \%$ & $4 \%$ & $15 \%$ & 0 & $\begin{array}{c}4 \\
\%\end{array}$ & $\begin{array}{c}15 \\
\%\end{array}$ \\
\hline
\end{tabular}

Table 4 Criteria of maturity of the general cultural competences in $\mathrm{CG}$ and $\mathrm{EG}$ in the beginning of the experiment and at its end

\begin{tabular}{|c|c|c|c|c|c|c|}
\hline \multirow{2}{*}{$\begin{array}{l}\text { Compet } \\
\text { ence } \\
\text { code }\end{array}$} & \multicolumn{2}{|c|}{$\begin{array}{l}\text { Experiment } \\
\text { start }\end{array}$} & \multirow{2}{*}{$\begin{array}{l}\text { Comp } \\
\text { arison }\end{array}$} & \multicolumn{2}{|c|}{$\begin{array}{l}\text { Experiment } \\
\text { end }\end{array}$} & \multirow{2}{*}{$\begin{array}{c}\text { Com } \\
\text { paris } \\
\text { on }\end{array}$} \\
\hline & $\mathrm{CG}$ & EG & & $\mathrm{CG}$ & $\mathrm{EG}$ & \\
\hline GC-1 & $64 \%$ & $60 \%$ & 45 & $66 \%$ & $71 \%$ & $+5 \%$ \\
\hline GC-2 & $59 \%$ & $57 \%$ & $2 \%$ & $63 \%$ & $63 \%$ & $=$ \\
\hline GC-3 & $63 \%$ & $63 \%$ & $=$ & $68 \%$ & $77 \%$ & $+9 \%$ \\
\hline GC-4 & $61 \%$ & $60 \%$ & $1 \%$ & $65 \%$ & $74 \%$ & $+9 \%$ \\
\hline GC-5 & $45 \%$ & $48 \%$ & $+3 \%$ & $51 \%$ & $59 \%$ & $+8 \%$ \\
\hline GC-6 & $57 \%$ & $58 \%$ & $+1 \%$ & $61 \%$ & $66 \%$ & $+5 \%$ \\
\hline GC-7 & $57 \%$ & $56 \%$ & $1 \%$ & $60 \%$ & $69 \%$ & $+9 \%$ \\
\hline GC-8 & $76 \%$ & $68 \%$ & $8 \%$ & $80 \%$ & $80 \%$ & $=$ \\
\hline GC-9 & $66 \%$ & $67 \%$ & $+1 \%$ & $73 \%$ & $73 \%$ & $=$ \\
\hline GC-10 & $68 \%$ & $65 \%$ & $3 \%$ & $71 \%$ & $75 \%$ & $+4 \%$ \\
\hline GC-11 & $65 \%$ & $62 \%$ & $3 \%$ & $69 \%$ & $74 \%$ & $+5 \%$ \\
\hline GC-12 & $62 \%$ & $61 \%$ & $1 \%$ & $67 \%$ & $73 \%$ & $+6 \%$ \\
\hline GC-13 & $64 \%$ & $63 \%$ & $+1 \%$ & $68 \%$ & $71 \%$ & $+3 \%$ \\
\hline
\end{tabular}




\begin{tabular}{|c|c|c|c|c|c|c|}
\hline GC-14 & $39 \%$ & $39 \%$ & $=$ & $53 \%$ & $57 \%$ & $+4 \%$ \\
\hline GC-15 & $40 \%$ & $39 \%$ & $1 \%$ & $47 \%$ & $53 \%$ & $+6 \%$ \\
\hline GC-16 & $77 \%$ & $77 \%$ & $=$ & $80 \%$ & $80 \%$ & $=$ \\
\hline GC-17 & $68 \%$ & $65 \%$ & $3 \%$ & $76 \%$ & $77 \%$ & $+1 \%$ \\
\hline
\end{tabular}

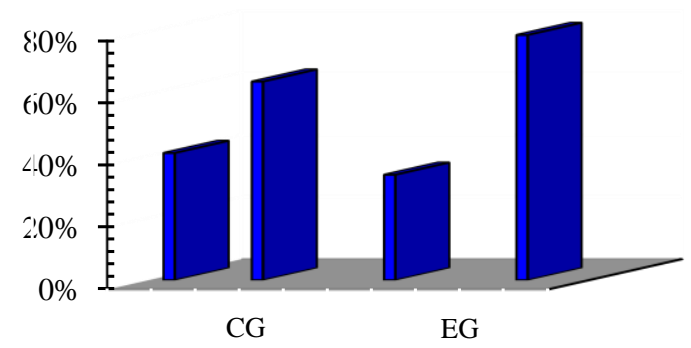

Fig.1. Bar graphs for Table 4

Comparison of the results obtained from implementation of the pedagogical conditions has shown, that in EG there is a significant level of the general cultural competence development.

Statistical methods were used for processing the data.

A complex implementation of pedagogical conditions for formation of the general cultural competences in implementation of the interdisciplinary approach allows for a conclusion that the institution of higher technical education holds the potential to form not just specialist capable of functioning in conditions of a constantly changing professional environment, but humane, creative, thinking individuals.

\section{Conclusion}

The experiment conducted in formation of the general cultural competences influenced the efficiency of formation of a competent specialist, prepared to professional life.

The materials of this research may be recommended to instructors of institutions of secondary and higher education to ensure development of the general cultural competences in students during the learning situation by means of the interdisciplinary approach and optimization of operation of institutions of professional education in the field of education quality improvement and formation of humane individuals.

This research does not pretend to be exhaustive and more studies are called for in this field.

\section{References}

1. R.T. Akhmetov, A.V. Andreev, \& V.V. Mukhametshin, Residual oil saturation and the displacement factor prediction methodology based on geophysical studies data to evaluate efficiency of nanotechnologies application, Nanotehnologii $v$ stroitel'stve = Nanotechnologies in Construction, 9(5), 116-133, (2017) DOI: 10.15828/2075-85452017-9-5-116-133.
2. L. Cox, L. Crump, R. Struwing, D. Gillum, \& S. Abraham, Building Cultural Competence: The Lived Experience of Semester Study Abroad Students. Journal of Christian Nursing, 34(3), E35E40. (2017).

3. R.M. Shaidullina, A.F. Amirov, V.S. Muhametshin, \& K.T. Tyncherov, Designing Economic Socialization System in the Educational Process of Technological University, European journal of contemporary education, 6(1), 149-158, (2017). DOI: 10.13187/ejced.2017.1.149

4. M.V. Goryunova, L.S. Kuleshova \& A.I. Khakimova, Application of signal analysis for diagnostics, International Conference on Industrial Engineering, Applications and Manufacturing (ICIEAM) (Saint Petersburg, 16-19 May 2017) / the team of authors. - SPb.: IEEE, 2017. - DOI: 10.1109/ICIEAM.2017.8076487.

5. R. Hack, S. Hekmat, \& L. Ahmadi, Canadian Journal of Dietetic Practice and Research, 76(4), 178-184, (2015).

6. G. R. Izmailova, L. A. Kovaleva, \& N. M. Nasyrov, High Temperature, 54(1), 56-61, (2016)

7. V.V. Mukhametshin, Eliminating uncertainties in solving bottom hole zone stimulation tasks, Bulletin of the Tomsk Polytechnic University. Geo Assets Engineering, 328 (7), 40-50, (2017)

8. M. R. Jeffreys, \& E. Dogan, Journal of Transcultural Nursing, 23(2), 188-197, (2012)

9. B. K. Jesiek, Y. Shen, \& Y Haller, International Journal of Engineering Education, 28(1), 144, (2012)

10. C. Nieto, \& M. Zoller Booth, Journal of Studies in International Education, 14(4), 406-425, (2010)

11. Yu.V. Zeigman, V.Sh. Mukhametshin, A.R. Khafizov, \& S.B. Kharina, Prospects of Application of Multi-Functional Well Killing Fluids in Carbonate Reservoirs, SOCAR Proceedings, 3, 3339, (2016). DOI: 10.5510/OGP20160300286.

12. A. C. Solano, \& I. Aristegui, Cultural Competences of International Students: It's Role on Successful Sociocultural and Psychological Adaptation. In Positive Psychology in Latin America (pp. 89-110). Springer, Dordrecht. (2014)

13. K.T. Tyncherov, V.Sh. Mukhametshin, \& L.B. Khuzina, Method to control and correct telemtry well information in the basis of residue number system, Journal of Fundamental and Applied Sciences, 9(2S), 1370-1374, (2017). DOI: 10.4314/jfas.v9i2s.848. 